\title{
The effectiveness of local steroid injection after internal urethrotomy to avoid recurrence
}

\author{
Mehmet Erol Yıldırım ${ }^{1}$, Mehmet Kaynar ${ }^{2}$, Ekrem Ozyuvali ${ }^{1}$, Huseyin Badem ${ }^{3}$, Muzaffer Cakmak ${ }^{4}$, \\ Bahadir Kosem $^{5}$, Ersin Cimentepe ${ }^{1}$ \\ ${ }^{1}$ Department of Urology, Turgut Özal University School of Medicine, Ankara, Turkey; \\ ${ }^{2}$ Department of Urology, Selçuk University School of Medicine, Konya, Turkey; \\ ${ }^{3}$ Department of Urology, Yüksek İhtisas Education and Research Hospital, Ankara, Turkey; \\ ${ }^{4}$ Department of Internal Medicine, Turgut Özal University School of Medicine, Ankara, Turkey; \\ ${ }^{5}$ Department of Anesthesiology, Turgut Özal University School of Medicine, Ankara, Turkey.
}

\begin{abstract}
Summary Objective: Local steroid injection to the stricture region after internal urethrotomy (IU) is a promising technique to avoid the recurrence, although the effectiveness and safety of this technique is still controversial. We aimed to determine the efficacy and safety of local steroids as applied with the IU procedure. Material-Method: A total of 83 patients data with urethral stricture in men were examined retrospectively. Patients classified in two groups who had steroid injection with internal urethrotomy or not. Metil prednisolone $40 \mathrm{mg}$ was injected with transurethral injection needle in the stricture region at the 5, 7 and 12 o'clock sites at the same session with internal urethrotomy. Procedure was considered successful if patient did not report any voiding difficulty and maximum flow rate $>15 \mathrm{~mL} / \mathrm{second}$ for a voided volume of at least $150 \mathrm{~mL}$ after removal of the catheter. Patient's age, time to recurrence, previous recurrences were evaluated. Results: The mean age was 56.4 (18-83) years. Of those patients 33/83 had recurrent stenosis. Nineteen out of these 33 recurrent stenosis patients were treated with local steroid injection and 14/33 had no injection. Only two patients of the steroid treated group had recurrence. Despite that 12 patients had recurrence in the steroid non-treated group. Also the primary stenosis patients showed no recurrence at the steroid+ IU group.

Conclusions: The use of local steroids with IU seems to decrease the high stricture recurrence rate following IU. When local steroids were administered with complementary intention, the disease control outcomes are encouraging. Further robust comparative effectiveness studies are now required.
\end{abstract}

KEY WORDS: Urethral stricture; Internal urethrotomy; Steroid; Recurrence.

Submitted 27 May 2015; Accepted 11 September 2015

\section{INTRODUCTION}

Urethral stricture is a well-known disease that has been known for centuries as far as ancient Greeks, Egyptians and Hindus (1). Difficulty on managing urethral strictures is its tendency to recur. First leading cause of urethral strictures was infection but, even with development of mankind and technologies, iatrogenic instrumenta- tions and external trauma take the lead. The actual incidence of urethral strictures developed after the transurethral resection of prostate is $2-10 \%$, as well as radical (8.4\%) and simple (1.9\%) prostatectomies (2-4). There are many treatment modalities as dilatation, endoscopic urethrotomy, stent placement and urethroplasty. Internal urethrotomy (IU) and dilatation are widely used for urethral strictures less than $2 \mathrm{~cm}$ with a success rate of $70 \%$ but also have a high rate of stricture recurrence (5-7). Although open urethroplasty is a highly successful and durable treatment method, surgeons don't perform it so often due to its invasiveness, longer catheterization requirement and need of experienced surgery skills (8). The recurrence of stricture occurs as a result of scar that forms into the urethral epithelium and decreases the caliber of urethra (9).

There are many investigations about use of drugs such as steroids, Mitomycin C, Hyaluronidsase to avoid this scar or keloid formation (10-12).

We aimed to investigate the combination of steroid injection with IU in order to avoid the recurrence of strictures and cure the patient with minimally invasive treatment.

\section{MateriaLS AND METHODS}

We present the data of patients from April 2009 to March 2014 in this retrospective study. The protocol was approved by the scientific and ethical committee of the university (2014/3255). Informed and signed consent was taken from all patients after explaining the nature of the study and the consequences of the procedure to be done in detail in their own language. Two surgeons performed internal urethrotomy with the same technique. Patients were divided into two groups by surgeons' preference to use steroid injection or not. Forty-one patients have been treated with IU adding steroid injection and 42 patients have been treated with only IU without steroid injections. Patients had option to opt out of the study at any time without compromising their right of treatment. A total of 83 male patients with diagnosed urethral strictures requiring optical internal urethrotomy were included in this study. Patients presenting for the first time for treatment

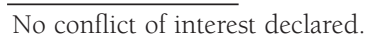


were referred to as primary, whereas those who had undergone some procedure for the treatment of stricture prior to reporting to us were referred as recurrent. In group A (IU only group); the patients underwent internal urethrotomy with cold knife. In group B (IU+ steroid group) metil prednisolone was injected to the stricture site after the internal urethrotomy with cold knife. Steroid was injected intralesional at the 5, 7 and 12 o'clock sites of urethrotomy using 22 G William's bladder injection needle (Cook Medical, Bloomington, USA). Forty $\mathrm{mg}$ metil prednisolone were injected for strictures less than $1 \mathrm{~cm}$ whereas the dosage increased to $40 \mathrm{mg}$ for each $\mathrm{cm}$ of stricture. The patients who had recurrence after steroid injection underwent a second IU+ steroid injection session. All of the recurrences were due to the transurethral resection of prostate.

Inclusion criteria were; presence of obstructive symptoms, peak flow rate on uroflowmetry less than $15 \mathrm{ml} / \mathrm{s}$ and short segment strictures (stricture length $<2 \mathrm{~cm}$ ) as evident on radiological studies, i.e. retrograde urethrography (RGU) and micturating cystourethrography (MCU). Exclusion criteria used were complete obliteration of urethral lumen on urethroscopy, Balanitis Xerotica Obliterans, age less than 18 years, multiple strictures, active urinary tract infection.

All patients were assessed by a history and a full physical examination, complete blood count, urine analysis, urine culture and sensitivity test, renal function tests, uroflowmetry and retrograde urethrography with micturating cystourethrography if needed. Urethroscopy was done with $20 \mathrm{~F}$ sheath and $0^{\circ}$ telescope. The site and length of the stricture along with the ability of telescope to pass through the stricture was noted on urethroscopy. The procedure was performed under spinal anesthesia at lithotomy position. Antibiotic (Ciprofloxacin, $500 \mathrm{mg}$ ) was given just before and $12 \mathrm{~h}$ after procedure and continued for next 7 days twice a day. Normal saline was used for irrigation during the procedure. Post-operative catheterization has been made by a $20 \mathrm{~F}$ urinary catheter. Post-operative catheterization time was 7 days.

Any symptoms pertaining to recurrence were noted as reduced stream of urine $(<10 \mathrm{~mL} / \mathrm{second})$, retention of urine ( $>50 \mathrm{ml}$ ), and burning micturition. Procedure was considered successful if patient did not report any voiding difficulty with maximum flow rate $>15 \mathrm{~mL} / \mathrm{second}$ for a voided volume of at least $150 \mathrm{~mL}$. Patients were followed up for at least 18 months.

Data were analyzed using SPSS software (the Statistical

Table 1.

Patients demoghraphic and laboratory data.

\begin{tabular}{|lccc|}
\hline & $\begin{array}{c}\text { Only IU } \\
\text { group (n: 42) }\end{array}$ & $\begin{array}{c}\text { IU+Steroid injection } \\
\text { group (n: 41) }\end{array}$ & p \\
\hline Age (years) & $61.5 \pm 16.2$ & $51.2 \pm 18.5$ & $0.397^{*}$ \\
\hline Follow up (month) & $30.1 \pm 17.3$ & $32 \pm 19$ & $0.634^{*}$ \\
\hline Hemoglobine (g/dL) & $14.1 \pm 1.95$ & $14.2 \pm 1.5$ & $0.838^{*}$ \\
\hline Neutrophile & $7500 \pm 2701$ & $7617 \pm 2567$ & $0.840^{*}$ \\
\hline History of recurrence & $14 / 42$ & $19 / 41$ & $0.681^{* *}$ \\
\hline $\begin{array}{l}\text { Number of recurrences } \\
\text { * Student t test performed. } \\
* * \text { Chi square test performed. } p<0.05 \text { considered the statistically significance. }\end{array}$ \\
\hline
\end{tabular}

Package for the Social Sciences, Version 14.0, SPSS Inc., Chicago, Illinois, USA). Normally distributed variables were described using means with standard deviations. Chi-square and student $t$ test were used to compare two groups. Non-normal distributed data were analyzed using Mann-Whitney U test. A p value less than 0.05 was considered statistically significant.

\section{Results}

The mean age at the presentation was 56.4 (18-83) years. Seventeen patients in the steroid group out of 41 needed $80 \mathrm{mg}$ metil prednisolone due to the length of the stricture. Only 2 patients had recurrence in the $80 \mathrm{mg}$ metil prednisolone treated group, whom also had a history of recurrence. So the success rate of the steroid injection was $95 \%$. And the recurrence rate of IU only treated group was $28 \%$ (Table 1).

Thirty-three out of 83 patients had a history of recurrent stenosis. Nineteen of these 33 patients were treated with local steroid injection and 14/ 33 had no injection. Two patients in the steroid treated group had recurrence at third and eighth month. On the contrary 12 patients had recurrence in the steroid non-treated group. Recurrence occurred at the first month in 9 patients and in the remaining patients at the second month of follow-up. Thus, for patients with history of recurrence, success rate was $89 \%$ for the first injection and $100 \%$ for the second injection.

In recurrence groups success rates of steroid injection was significantly higher than the IU only treated patients ( $89 \%$ versus $14.2 \%$ respectively, $\mathrm{p}=0.021$ ). Time to recurrence was significantly lower in the IU than the steroid group ( $1.2 \pm 0.4$ months, $6 \pm 2.5$ months, respectively, $\mathrm{p}=0.03$ ).

\section{Discussion}

The main problem of urologists in relation to urethral stricture is not the disease itself but its nature of recurrence. Open urethroplasty has better results especially if performed at the early stage, but it requires a certain expertise and a long period of catheterization (13). Optical internal urethrotomy is another standard treatment of urethral strictures with varying success rates although not as good as open urethroplasty (14). In a survey conducted by the American Urology Association, $86 \%$ of the urologists performed IU for urethral strictures probably because of unfamiliarity and lack of expertise in open urethroplasty (15). In a study with 224 patients, the recurrence rate was reported as $68 \%$ after the first IU, 96\% after the second IU and 100\% after the third procedure (16). Recurrent IUs also decrease the success rates of the urethroplasty (17). So that investigators are searching for minimally invasive and curative treatment modalities for a long time.

The main pathogenesis of stricture is the fibrosis formation caused by excessive collagen synthesis and changes in the extracellular matrix of the urethral lumen due to the endoscopic instrumentations, trauma and infections (18). Spongiofibrosis occurs in varying degrees and narrows the urethral luminal caliber. So that there are some 
ideas of treating the fibrosis with antifibrotic agents such as halofugione, mitomycin $\mathrm{C}$, bitoxin $\mathrm{A}$, somatostatin analogues, captopril and steroids (11, 19-23).

There have been a few prospective randomized clinical trials in recent literature on comparative study of steroid injection after IU over conventional cold knife for internal urethrotomy. In a study, recurrence rate after IU was reported as varying $50 \%$ to $75 \%$ in a 2 years follow up period (24). We reported a $28 \%$ rate of recurrence in the IU only treated group. Our success rates may be due to our IU technique. Common practice among urologists is one cut at 12 o' clock to incise the stricture (86.3\%) (8). But a deep cut at this site may cause erectile dysfunction, extravasation and incontinence $(25,26)$. So we prefer to cut the 5, 7 and 12 o' clock sites to avoid above complications and to decrease the tension of the stricture.

Korhonnen et al injected $80 \mathrm{mg}$ triamcinolone to 17 of 21 patients after IU only to the 12 o'clock position and removed the catheter the day after the surgery. Although the IU only group had a $71 \%$ recurrence rates, steroid injected group had $61 \%$ recurrence rates (27). In another study, Tabassi et al. performed internal urethrotomy and triamcinolone injection in 34/70 patients with stricture. They noted a recurrence rate of $35.2 \%$ in the steroid injected and $41.6 \%$ in IU only group. Although there were no statistically significant difference between the two groups (p: 0.584), time to recurrence significantly decreased in the triamcinolone treated group $(p<0.05)$ (28). In our study we observed that steroid injection prolonged the recurrence time significantly from 1,2 to 6 months $(p<0.03)$. In addition to that, we removed the catheter at the seventh day after the surgery. Kumar et al. also reported a $95.8 \%$ success rate in patient treated with holmium laser and $80 \mathrm{mg}$ of triamcinolone (29). We have found a recurrence rate of $5 \%$ in the steroid group rather than $28 \%$ in IU only treated group. Also in the patients with recurrent stenosis, the success rates were better than the IU only treated group (89\% versus $14.2 \%$ respectively, $\mathrm{p}=0.021$ ).

Several adjuvant therapies including injection of docetaxel, captopril, mitomycin C, hyaluronidase have been also proposed to avoid the recurrence after the IU $(10,11,18,23)$. Chung et al. studied the effectiveness of hyaluronidase injection to the stricture site and found a recurrence rate of $9.4 \%$ and $22.9 \%$ respectively in the injection and in the control group (12). A recurrence rate of $2 \%$ versus $50 \%$ was reported in patients treated with Mitomycin $\mathrm{C}$ injection or not, in a small study consisting of 40 patients (11). In a rabbit model, it has been shown that docetaxel significantly inhibited the urethral stricture formation (18). No complications were noted due to the steroid injections. Despite the benefits of these materials, steroids comes a step forward so as to its cost effectiveness, lower side effects and also widespread usage in general medicine.

\section{Conclusion}

The clinical decision of stricture-recurrence-prevention techniques should be carefully tailored to every individual patient. Steroid injection to the stricture site to avoid fibrosis is a safe and effective adjuvant therapy for short segment strictures after internal urethrotomy. Metil prednisolone injection during internal urethrotomy may decrease the recurrence rate significantly. As the course of urethral stricture recurrence is rather long spreading over many years, further comparative studies with longer follow-ups are required to accurately evaluate the effect of steroid injection.

\section{REFERENCES}

1. Webster GD, Koefoot Rb, Sihelnik SA. Urethroplasty management in 100 cases of urethral sticture: a rationale for procedure selection. J Urol. 1985; 134:892-898.

2. Rassweiler J, Teber D, Kuntz R, Hofmann R. Complications of Transurethral Resection of the Prostate (TURP) incidence, management, and prevention. Eur Urol. 2006; 50:969-80.

3. Elliott SP, Meng MV, Elkin EP, et al. Incidence of urethral stricture after primary treatment for prostate cancer:Data From CaPSURE. J Urol. 2007; 178:529-34.

4. Varkarakis I, Kyriakakis Z, Delis A, et al. Long-term results of open transvesical prostatectomy from a contemporary series of patients. Urology. 2004; 64:306-10.

5. Naude AM, Heyns CF. What is the place of internal urethrotomy in the treatment of urethral stricture disease? Nat Clin Pract Urol. $2005 ; 2: 538-45$.

6. Albers P, Fitchner J, Bruhl P, Muller SC. Long term results of internal urethrotomy J Urol. 1996; 156:1611-1614.

7. Chilton CP, Shah PJ, Fowler CG, et al. The impact of optical urethrotomy on the management of urethral stricutres. Br J Urol. 1983; 55:705-710.

8. Ferguson GG, Bullock TL, Anderson RE, et al. Minimally invasive methods for bulbar urethral strictures: a survey of members of the American Urological Association. Urology. 2011; 78:701-6.

9. Latini JM. Minimally invasive treatment of urethral strictures in men. Current Bladder Dysfunction Reports. 2008; 3:111-6.

10. Kumar S, Garg N, Singh SK, Mandal AK. Efficacy of Optical Internal Urethrotomy and Intralesional Injection of Vatsala-Santosh PGI Tri-Inject (Triamcinolone, Mitomycin C, and Hyaluronidase) in the Treatment of Anterior Urethral Stricture. Adv Urol. 2014; 2014:192710.

11. Mazdak H, Meshki I, Ghassami F. Effect of mitomycin C on anterior urethral stricture recurrence after internal urethrotomy. Eur Urol. 2007; 51:1089-92.

12. Chung JH, Kang DH, Choi HY, et al. The effects of hyaluronic acid and carboxymethylcellulose in preventing recurrence of urethral stricture after endoscopic internal urethrotomy: a multicenter, randomized controlled, single-blinded study. J Endourol. 2013; 27:756-62.

13. Langston J, Robson C, Rice K, et al. Synchronous urethral stricture reconstruction via 1-stage ascending approach: rationale and results. J Urol. 2009; 181: 2161-2165.

14. Jain SK, Kaza RC, Singh BK. Evaluation of holmium laser versus cold knife in optical internal urethrotomy for the management of short segment urethral stricture. Urol Ann. 2014; 6:328-33.

15. Hradec E, Jarolim L, Petrik R. Optical internal urethrotomy for strictures of the male urethra: Effect of local steroid injection. Eur Urol. 1981; 7:165-168.

16. Pansodoro V, Emiliozzi P. Internal urethrotomy in the management of anterior urethral strictures: long term follow-up. J Urol. 1996; 156:73-75. 
17. Roehrborn CG, McConnell JD. Analysis of factors contributing to success or failure of 1-stage urethroplasty for urethral stricture disease. J Urol. 1994; 151:869-874.

18. Fu D, Chong T, Li H, et al. Docetaxel inhibits urethral stricture formation, an initial study in rabbit model. PLoS One. 2014; 9:e112097.

19. Nagler A, Gofrit O, Ohana M, et al. The effect of halofuginone, an inhibitor of collagen type I synthesis, on urethral stricture formation: in vivo and in vitro study in a rat model. J Urol. 2000; 164:1776-1780

20. Khera M, Boone TB, Smith CP. Botulinum toxin type A: a novel approach to the treatment of recurrent urethral strictures. J Urol. 2004; 172:574-575.

21. Andersen H, Duch B, Gregersen H, et al. The effect of the somatostatin analogue lanreotide on the prevention of urethral strictures in a rabbit model. Urol Res. 2003; 31:25-31.

22. Sciarra A, Salciccia S, Albanesi L. Use of cyclooxygenase-2 inhibitor for prevention of urethral strictures secondary to transurethral resection of the prostate. Urol Res. 2005; 66:1218-1222.

23. Shirazi M, Khezri A, Samani SM, et al. Effect of intraurethral cap- topril gel on the recurrence of urethral stricture after direct vision internal urethrotomy: Phase II clinical trial. Int J Urol. 2007; 14:203-8

24. Holm-Nielsen A, Schultz A, Moller-Pedersen V. Direct vision internal urethrotomy: A critical review of 365 operations. Br J Urol. 1984; 365:308-12.

25. Santucci R, Eisenberg L. Urethrotomy has a much lower success rate than previously reported. J Urol. 2010; 183:1859-1962.

26. Albers P, Fichtner J, Brühl P, Müller SC. Long-term results of internal urethrotomy. J Urol. 1996; 156:1611-1614.

27. Korhonen P, Talja M, Ruutu M, Alfthan O. Intralesional corticosteroid injections in combination with internal urethrotomy in the treatment of urethral strictures. Int Urol Nephrol. 1990; 22:263-9.

28. Tabassi KT, Yarmohamadi A, Mohammadi S. Triamcinolone injection following internal urethrotomy for treatment of urethral stricture. Urol J. 2011; 8:132-6.

29. Kumar S, Kapoor A, Ganesamoni R, et al. Efficacy of holmium laser urethrotomy in combination with intralesional triamcinolone in the treatment of anterior urethral stricture. Korean J Urol. 2012; 53:614-8.

\section{Correspondence}

Mehmet Erol Yildirm, MD (Corresponding Author)

doctorerol@yahoo.com

Ekrem Ozyuvali, MD

Ersin Cimentepe, $M D$

Department of Urology, Turgut Özal University School of Medicine 06510, Yenimahalle Ankara, Turkey

Mehmet Kaynar, MD

Department of Urology, Selçuk University School of Medicine, Konya, Turkey

Huseyin Badem, MD

Department of Urology, Yüksek İhtisas Education and Research Hospital Ankara, Turkey

\section{Muzaffer Cakmak, MD}

Department of Internal Medicine,Turgut Özal University School of Medicine Ankara, Turkey

Bahadir Kosem, MD

Department of Anesthesiology, Turgut Özal University School of Medicine Ankara, Turkey 